\title{
Estimates of covariance components for hygienic behavior in Africanized honeybees (Apis mellifera)
}

\author{
Fabiana Martins Costa-Maia ${ }^{1}$, Vagner de Alencar Arnaut de Toledo $^{1}$, Elias Nunes Martins ${ }^{1}$, \\ Daniela Andressa Lino-Lourenço ${ }^{1}$, Maria Josiane Sereia ${ }^{2}$, Carlos Antonio Lopes de Oliveira ${ }^{1}$, \\ Patrícia Faquinello ${ }^{1}$, André Luiz Halak ${ }^{1}$
}

\author{
1 Universidade Estadual de Maringá. \\ 2 Universidade Tecnológica Federal do Paraná - Campus de Campo Mourão.
}

\begin{abstract}
Genetic and phenotypic parameters considering the genetic effect on hygienic behavior of queen and workers from 40 Africanized honeybees colonies were estimated separately. Maternal origin of queens was controlled whereas the paternal was unknown, and different groups of workers were considered in three seasons, October 2006, April 2007 and August 2007, but with the same queen. Colonies were 21 honey producers and 19 royal jelly producers. After the method of freezing capped brood, hygienic behavior was determined by the ratio between the number of dead capped brood removed at 24, 48 and 72 hours and the total number of capped brood at zero hour. Data was submitted to single and three traits analyses using Bayesian inference. Estimates of direct heritability at 24, 48 and 72 hours $(0.10,0.11$ and 0.11$)$ were identical to the motherly ones. Estimates by three trait analysis of direct heritability were $0.28,0.15,0.24$, and of maternal heritability were $0.23,0.29,0.27$, at 24,48 and 72 hours, respectively. Correlations between maternal and genetic effects were $0.12,0.09$ and -0.08 at, 24, 48 and 72 hours, respectively. Correlation between 24 and 48 hours was 0.49 ; between 24 and 72 hours, 0.40; and between 48 and 72 hours, 0.47. Moderate genetic correlations with the number of capped brood removed until 48 and 72 hours indicate that after the selection of a few generations, these traits can become an efficient criterion for selection in 24 hours.
\end{abstract}

Key Words: Africanized honeybee queens, Bayesian inference, genetic correlation, heritability, maternal effect, removal of dead capped brood

\section{Introduction}

Hygienic behavior is a natural mechanism of resistance to diseases, including American Putrid Brood and Chalkbrood (Milne, 1983; Gilliam et al., 1989; Spivak \& Gilliam, 1993), characterized by uncapping and removing dead, sick or damaged brood from the honeycomb. Rothenbühler (1964) conducted the first genetic study for this trait and concluded that hygienic behavior is regulated by two loci of recessive genes. Recently, Lapidge et al. (2002) found seven loci that may be involved in controlling this behavior.

Chevalet \& Cournet (1982) suggested that performance and behavior of the colony result from the interaction between queen and worker bees. Those authors adapted the model developed by Willham (1963) - which separates the estimative of heritability for maternal and direct effect - for bees. Behavior is an inherited characteristic, genetically determined, but not always expressed, depending on factors such as population, force of the colony and some that are still unknown
(Spivak \& Gilliam, 1993; Rothenbühler, 1964; Lapidge et al., 2002). According to Bienefeld et al. (2007), the queen transmits half of her genes, and still offers environmental contribution to her worker daughters through quality and quantity of produced eggs and production of pheromones. Therefore, the genotype of the queen determines, at least in part, this behavior. Those authors proposed the use of a BLUP (Best Linear Unbiased Predictor) animal model with adaptations for bees, considering the effects of queen and workers, environmental and kinship effects.

The accuracy in estimating genetic value of individuals depends on genetic differences of population, environment, analyses, estimation method of covariance components and, mostly, on the effects considered in the statistical model used to evaluate the animals.

Therefore, this study was done to estimate genetic and phenotypic parameters of Africanized honeybees colonies with naturally fertilized queens, separately, considering the genetic effect of queen and workers on hygienic behavior at 24,48 and 72 hours. 


\section{Material and Methods}

The experiment was performed at Fazenda Experimental de Iguatemi from Universidade Estadual de Maringa (FEI-UEM) in October 2006, April 2007 and August 2007, featuring three different periods. The honeybee colonies were 40 Africanized honeybees (Apis mellifera): 21 housed in Langstroth hives with 10 honeycombs for honey production, and 19 in mini-hive system (Santos \& Message, 1980) for royal jelly production.

Colonies were orphaned and received naturally fertilized virgin queens with controlled maternal origin identified with a numbered plate on thorax. The queen breeders that gave rise to these queens were brought randomly from commercial apiaries from the northern region of Paraná, western São Paulo and Paraguay, and had no history of performance.

Doolittle's method (1889) was used for the production of queens. Larvae age was used until one day of age, and queen cells were removed ten days after the larvae's transfer to be emerged in controlled laboratory oven.

The development cycle of an Africanized worker is 20 days (Nogueira-Couto \& Couto, 2006) and the average longevity is 26.3 days, according to Terada et al. (1975), for colonies ranging from 37,000 to 42,000 individuals. Thus, all the workers present in colony after approximately 45 days are daughters of the new queen. Evaluation of hygienic behavior was performed after that period, according to the method established by Rothenbühler (1964), Newton et al. (1975) and revised by Spivak \& Downey (1998). That method defines the time spent by the colonies to detect, uncap and remove the brood killed by freezing $\left(-20^{\circ} \mathrm{C}\right.$ for 24 hours), from a honeycomb section of $5 \times 6 \mathrm{~cm}$ (approximately 100 cells of larvae and/or capped brood on each side of the honeycomb), that had been cut from the nest of the colony to be evaluated.

Prior to being returned to their colony of origin, the section of honeycomb was thawed in laboratory oven at $34^{\circ} \mathrm{C}$ and $60 \%$ humidity during four hours for drying and establishment of the same internal temperature of the colony. Later, the section was photographed and mapped for the quantification of capped, uncapped and removed brood cells on both sides of the honeycomb at zero, 24, 48 and 72 hours.

Estimates for hygienic behavior were obtained using the following formula:

$$
C H_{x}=\left(T O_{\text {zerohour }}-A O_{x}\right) / T O_{\text {zerohour }}
$$

where: $\mathrm{CH}_{x}=$ ratio between the number of cells that have been cleaned and the total number of capped cells at zero hour, in which $_{x}$ stands for 24, 48 and 72 hours, $T O_{\text {zerohour }}=$ total number of capped cells at zero hour; $A O_{x}=$ total number of capped cell in which ${ }_{x}$ stands for 24, 48 and 72 hours.

A different group of workers was considered for each period of this experiment, and each group was treated as an individual. However, the kinship between groups is half-sisters, because the same queen remained in the three seasons.

The analyzed data refer to hygienic behavior measured at 24, 48 and 72 hours of 64 individuals among queens (24) and colonies (40), where 88 animals were counted in the kinship matrix.

Estimation of covariance components for all hygienic behavior traits at 24 hours (CH24), 48 hours (CH48) and 72 hours (CH72) was performed by the MTGSAM (Multiple Trait Gibbs Sampling in Animal Models) software, developed by Van Tassel \& Van Vleck (1995), proceeding the Bayesian estimation by Gibbs' sampling method.

Single and three trait analyses were performed using a model that included fixed effects of period and category of production; the direct genetic effects of honeybee workers and the permanent effects of environment and maternal genetics of the queen.

Presumptions were: fixed effects with uniform distribution, random effects with normal distribution and the covariance components with Wishart or Gamma reversed distribution.

The model used to estimate covariance components and genetic parameters for the percentage of hygienic behavior at 24, 48 and 72 hours was:

$$
\mathrm{Y}=\mathrm{X} \beta+\mathrm{Zu}+\mathrm{e} \text {, where: } \mathrm{Z}=\left[Z_{1} Z_{2} Z_{3}\right] ; u=\left[\begin{array}{l}
g \\
p
\end{array}\right] \text { and }
$$

$g=\left[\begin{array}{l}a \\ m\end{array}\right]$

where: $\mathrm{Y}=$ vector of observations; $\mathrm{X}, \mathrm{Z}_{1}, \mathrm{Z}_{2}$ and $\mathrm{Z}_{3}=$ incidence matrix for fixed effects, direct genetic effects, maternal effects and environmentally permanent effects, respectively; $\beta, \mathrm{a}, \mathrm{m}, \mathrm{p}$ and $\mathrm{e}=$ vector of fixed effects, direct genetic effects, maternal effects, permanent environmental and waste effects, respectively.

The joint distribution of $y, g, m, p$ and e vectors can be described as follows:

$$
\left[\begin{array}{c}
y \\
u \\
e
\end{array}\right] \sim N M V\left\{\left[\begin{array}{c}
X \beta \\
0 \\
0
\end{array}\right] ;\left[\begin{array}{ccc}
V & Z \sum & R \otimes I_{n} \\
\sum Z & \sum & 0 \\
R \otimes I_{n} & 0 & R \otimes I_{n}
\end{array}\right]\right\}
$$

where: $V=Z \sum Z^{\prime}+R \otimes I_{n} \quad \sum=\left[\begin{array}{cc}G \otimes A & 0 \\ 0 & P \otimes I_{m}\end{array}\right]$ 


$$
\begin{aligned}
& G=\left[\begin{array}{cccccc}
\sigma_{a_{1}}^{2} & \sigma_{a_{1} a_{2}} & \sigma_{a_{1} a_{3}} & \sigma_{a_{1} m_{1}} & \sigma_{a_{1} m_{2}} & \sigma_{a_{1} m_{3}} \\
& \sigma_{a_{2}}^{2} & \sigma_{a_{2} a_{3}} & \sigma_{a_{2} m_{1}} & \sigma_{a_{2} m_{2}} & \sigma_{a_{2} m_{3}} \\
& & \sigma_{a_{3}}^{2} & \sigma_{a_{3} m_{1}} & \sigma_{a_{3} m_{2}} & \sigma_{a_{3} m_{3}} \\
\text { Symmetrical } & & & \sigma_{m_{1}}^{2} & \sigma_{m_{1} m_{2}} & \sigma_{m_{1} m_{3}} \\
& & & & \sigma^{2}{ }_{m_{2}} & \sigma_{m_{m_{2}} m_{3}} \\
& & & & & \sigma^{2}{ }_{m_{3}}
\end{array}\right] \\
& P=\left[\begin{array}{ccc}
\sigma_{p_{1}}^{2} & \sigma_{p_{1} p_{2}} & \sigma_{p_{1} p_{3}} \\
& \sigma_{p_{2}}^{2} & \sigma_{p_{2} p_{3}} \\
\text { Symmetrical } & & \sigma_{p_{3}}^{2}
\end{array}\right] \quad R=\left[\begin{array}{ccc}
\sigma_{e_{1}}^{2} & \sigma_{e_{1} e_{2}} & \sigma_{e_{1} e_{3}} \\
& \sigma_{e_{2}}^{2} & \sigma_{e_{2} e_{3}} \\
\text { Symmetrical } & & \sigma_{e_{3}}^{2}
\end{array}\right]
\end{aligned}
$$

where: $V=$ matrix of phenotypic variances and covariances among traits, $G$ is the matrix of genetic variance and covariance among direct and maternal characteristics $\mathrm{CH}_{24}$, $\mathrm{CH}_{48}$ and $\mathrm{CH}_{72} ; \mathrm{A}=$ matrix that relates the individuals genetically; $P$ = matrix of variances and covariances of the environmentally permanent effects; $I_{m}=$ identity matrix with order equal to the number of mothers; $R=$ matrix of residual covariances among traits; $I_{n}=$ identity matrix with order $\mathrm{n}$ equal to the number of observations.

Chains of Gibbs were generated for the single-trait analyses, with 8,550,000 iterations for $\mathrm{CH}_{24}$, and 6,550,000 iterations for $\mathrm{CH}_{48}$ and $\mathrm{CH}_{72}$, whereas for three trait analysis, chains of Gibbs with 230,000,000 iterations were generated. The initial discard was 50,000 and the sampling interval was one thousand iterations for all analyses. Credibility intervals and regions of high density were constructed for all the covariance components and genetic parameters estimated at the $90 \%$ level of credibility.

Convergence monitoring of chains was performed with Heidelberger and Welch diagnostic tests, available in CODA library (Convergence Diagnosis and Output Analysis), implemented in the R software (2007).

\section{Results and Discussion}

Hygienic behavior means and standard deviations at 24, 48 and 72 hours were $0.76 \pm 0.22,0.88 \pm 0.17$ and $0.92 \pm 0.15$, respectively. All colonies were analyzed, and $15.63,23.44$ and $12.5 \%$ removed all the dead capped brood at 24, 48 and 72 hours respectively. According to Spivak \& Downey (1998), a colony must be considered hygienic if, within 48 hours, more than $95 \%$ of brood from the honeycomb section had been removed in two repetitions of the test. In this study, $42.19 \%$ of the colonies were classified in this condition.

There was an indicative of convergence for all chains when diagnostic tests for single and three-trait analyses were performed. Estimates of covariance components were accurate, with symmetric posterior distributions, because credible intervals presented low amplitudes and high density areas (HDA) equal or very close to the credible intervals. According to Casella \& George (1992), credible intervals can be defined according to posterior HAD of parameter when the distribution is symmetrical. High density area is that which contains ( 1 - a) 100\% posterior probability, where a is the level of significance.

Estimates of $\mathrm{CH}_{24}, \mathrm{CH}_{48}$ and $\mathrm{CH}_{72}$ in single trait analysis were very similar (Table 1). Values estimated for direct, maternal, environmentally permanent, residual and phenotypic additive variances indicated variability.

Direct and maternal heritability estimates were similar and presented low magnitude (Table 1). This indicates the similar influence of queen and workers at the three periods and the significant influence of the environment. Gill \& Kerr (1970) defined this behavior as highly influenced by the environment.

Direct heritability values are similar to those found by Milne (1985), which estimated 0.14 for uncapping and 0.02 for removal of dead capped brood.

Covariance estimates between direct and maternal genetic effects showed equal means of - 0.001 , with credible intervals from -0.006 to 0.004 , from -0.004 to 0.002 and from -0.004 to 0.002 for $\mathrm{CH}_{24}, \mathrm{CH}_{48}$ and $\mathrm{CH}_{72}$, respectively. Within the same order, estimated high density regions were: from - 0.006 to 0.004 , from - 0.004 to 0.002 , and from 0.003 to 0.002 . As a function of that, credible intervals were broad featuring estimates with low accuracy, but with symmetric posterior distributions. According to Bienefeld \& Pirchner (1990), negative correlation can be found in bees, as also occurs in other species.

When three trait analysis was performed, estimates were accurate with symmetrical posterior distribution (Table 2). Direct and maternal genetic variance estimates were between 0.02 (for hygienic behavior at 48 and 72 hours) and 0.03 (hygienic behavior at 24 hours); and between 0.02 (hygienic behavior at 24 and 72 hours) and 0.05 (hygienic behavior at 48 hours), respectively, and were higher than those found in single-trait analysis.

Covariance between direct and maternal genetic effects presented negative values, except where maternal genetic effect for hygienic behavior at 48 hours was associated with direct genetic effects of hygienic behavior at 24, 48 and 72 hours respectively. The negative values reflected the antagonism between direct and maternal genetic effects.

Queens from the colonies tested for hygienic behavior were the same during the three periods, so their effect in the model was maternal genetic and also environmentally permanent. 
Table 1 - Estimates of direct $\left(\sigma_{a}^{2}\right)$, maternal $\left(\sigma_{m}^{2}\right)$, environmentally permanent $\left(\sigma_{i}^{2}\right)$, residual $\left(\sigma_{e}^{2}\right)$ and phenotypical $\left(\sigma_{y}^{2}\right)$ variance, direct heritability $\left(h_{a}^{2}\right)$, maternal heritability $\left(h_{m}^{2}\right)$ and the genetic correlation between direct and maternal effects $\left(r_{g_{a m}}\right)$ with their credible intervals and high density area at $90 \%$ in trait analysis for hygienic behavior in Africanized honeybees

\begin{tabular}{|c|c|c|c|}
\hline Component* & Estimate & Credible intervals & Region of high density \\
\hline$\sigma_{a 1}^{2}$ & 0.006 & $0.01-0.02$ & $0.01-0.01$ \\
\hline$\sigma_{a 2}^{2}$ & 0.004 & $0.01-0.01$ & $0.01-0.01$ \\
\hline$\sigma_{a 3}^{2}$ & 0.004 & $0.002-0.009$ & $0.002-0.008$ \\
\hline$\sigma_{m 1}^{2}$ & 0.006 & $0.01-0.01$ & $0.01-0.01$ \\
\hline$\sigma_{m 2}^{2}$ & 0.004 & $0.002-0.01$ & $0.002-0.01$ \\
\hline$\sigma_{m 3}^{2}$ & 0.004 & $0.002-0.01$ & $0.002-0.01$ \\
\hline$\sigma_{p 1}^{2}$ & 0.006 & $0.01-0.01$ & $0.01-0.01$ \\
\hline$\sigma_{p 2}^{2}$ & 0.004 & $0.002-0.01$ & $0.01-0.01$ \\
\hline$\sigma_{p 3}^{2}$ & 0.004 & $0.001-0.01$ & $0.001-0.01$ \\
\hline$\sigma_{e 1}^{2}$ & 0.05 & $0.03-0.06$ & $0.03-0.06$ \\
\hline$\sigma_{e 2}^{2}$ & 0.03 & $0.02-0.04$ & $0.02-0.04$ \\
\hline$\sigma_{e 3}^{2}$ & 0.02 & $0.02-0.04$ & $0.02-0.03$ \\
\hline$\sigma_{y 1}^{2}$ & 0.06 & $0.05-0.08$ & $0.05-0.08$ \\
\hline$\sigma_{y 2}^{2}$ & 0.04 & $0.03-0.06$ & $0.03-0.06$ \\
\hline$\sigma_{y 3}^{2}$ & 0.04 & $0.03-0.05$ & $0.03-0.05$ \\
\hline$h_{a 1}^{2}$ & 0.10 & $0.03-0.24$ & $0.03-0.19$ \\
\hline$h_{a 2}^{2}$ & 0.11 & $0.04-0.23$ & $0.03-0.20$ \\
\hline$h_{a 3}^{2}$ & 0.11 & $0.04-0.22$ & $0.03-0.19$ \\
\hline$h_{m 1}^{2}$ & 0.10 & $0.03-0.19$ & $0.03-0.16$ \\
\hline$h_{m 2}^{2}$ & 0.11 & $0.04-0.22$ & $0.01-0.11$ \\
\hline$h_{m 3}^{2}$ & 0.11 & $0.05-0.22$ & $0.03-0.19$ \\
\hline$r g_{a_{1} m_{1}}$ & -0.09 & $-0.68-0.53$ & $-0.68-0.53$ \\
\hline$r g_{a_{2} m_{2}}$ & -0.10 & $-0.63-0.47$ & $-0.67-0.44$ \\
\hline$r g_{a_{3} m_{3}}$ & -0.09 & $-0.61-0.46$ & $-0.62-0.44$ \\
\hline
\end{tabular}

* For all estimates, a, m, i, e and y represent direct, maternal, permanent environmental, residual and phenotypical genetic effects, respectively. Indices 1 , 2 and 3 represent hygienic behavior at 24,48 and 72 hours, respectively.

Variance estimates of permanent environmental effect were higher in three trait analysis than those found in single trait analysis (Table 3). Accuracy was similar with symmetrical posterior distribution for hygienic behavior at 24 and 72 hours. When assessed at 48 hours, hygienic behavior presented the highest estimate, with less accurate credible interval. Estimates for covariance between environmental permanent effects presented broad credible intervals and symmetrical posterior distribution.

Estimates of residual variance generated values of 0.02 (hygienic behavior at 48 and 72 hours) and 0.03 (hygienic behavior at 24 hours) and the residual covariance was 0.01 and 0.02 (Table 4). All estimates were accurate in three-trait analysis with symmetrical posterior distribution (Table 2). And these estimates were higher in single-trait analysis.

Estimates of phenotypic variance, which represents the random portion of the model in study ranged from 0.08 to 0.19 (Table 5) and presented higher accuracy at 24 and 72 hours. Once again, the estimate involving hygienic behavior at 48 hours was higher and less accurate.

The sum of genetic and environmental effects of the queen on hygienic behavior at 24, 48 and 72 hours accounted for 45.5, 68.4 and $50.0 \%$ of phenotypic variation, respectively. Isolating these effects, the contribution of maternal effects to phenotypic variance was 18.2, 26.3 and $25.0 \%$, and to permanent environmental variance, it was 27.3, 42.1 and $25.0 \%$, for hygienic behavior at 24, 48 and 72 hours, respectively. Workers have contributed to the phenotypic variance of features with 27.3, 10.5 and $25.0 \%$, respectively.

Estimates for additive, maternal, permanent environmental and "permanent environmental covariances" in three trait analysis were higher than the residuals and lower than the ones found in single trait analysis. This is a result from the increased number of information considered in the three trait analysis.

Therefore, the choice between three trait or single trait analysis must be based on estimates of heritability and correlations among them (Table 6).

All estimates were accurate with symmetrical posterior distribution. Estimates of direct and maternal heritability for hygienic behavior were higher than those found for single trait analysis. This proves that the three trait analysis contributed to retrieving a larger portion of additive genetic variance. 
Table 2 - Estimates of direct and maternal additive genetic covariance components with respective credible intervals and high density areas at $90 \%$ in three trait analysis for hygienic behavior of Africanized honeybees

\begin{tabular}{|c|c|c|c|}
\hline Component* & Estimate & Credible intervals & Region of high density \\
\hline$\sigma_{a_{1}}^{2}$ & 0.03 & $0.01-0.05$ & $0.01-0.04$ \\
\hline$\sigma_{a_{1} a_{2}}$ & 0.01 & $0.002-0.03$ & $0.0004-0.02$ \\
\hline$\sigma_{a_{1} a_{3}}$ & 0.01 & $0.0005-0.02$ & $-0.001-0.02$ \\
\hline$\sigma_{a_{1} m_{1}}$ & -0.003 & $-0.02-0.01$ & $-0.02-0.01$ \\
\hline$\sigma_{a_{1} m_{2}}$ & 0.003 & $-0.02-0.03$ & $-0.02-0.03$ \\
\hline$\sigma_{a_{1} m_{3}}$ & -0.0003 & $-0.01-0.01$ & $-0.01-0.01$ \\
\hline$\sigma_{a_{2}}^{2}$ & 0.02 & $0.01-0.04$ & $0.01-0.03$ \\
\hline$\sigma_{a_{2} a_{3}}$ & 0.01 & $0.002-0.02$ & $0.001-0.02$ \\
\hline$\sigma_{a_{2} m_{1}}$ & -0.001 & $-0.01-0.01$ & $-0.01-0.01$ \\
\hline$\sigma_{a_{2} m_{2}}$ & 0.003 & $-0.02-0.03$ & $-0.02-0.02$ \\
\hline$\sigma_{a_{2} m_{3}}$ & -0.001 & $-0.01-0.01$ & $-0.01-0.01$ \\
\hline$\sigma_{a_{3}}^{2}$ & 0.02 & $0.01-0.03$ & $0.01-0.03$ \\
\hline$\sigma_{a_{3} m_{1}}$ & -0.001 & $-0.01-0.01$ & $-0.01-0.01$ \\
\hline$\sigma_{a_{3} m_{2}}$ & 0.003 & $-0.01-0.02$ & $-0.01-0.02$ \\
\hline$\sigma_{a_{3} m_{3}}$ & -0.002 & $-0.01-0.01$ & $-0.01-0.01$ \\
\hline$\sigma_{m_{1}}^{2}$ & 0.02 & $0.01-0.04$ & $0.01-0.04$ \\
\hline$\sigma_{m_{1} m_{2}}$ & 0.002 & $-0.01-0.02$ & $-0.01-0.02$ \\
\hline$\sigma_{m_{1} m_{3}}$ & 0.004 & $-0.01-0.01$ & $-0.01-0.02$ \\
\hline$\sigma_{m_{2}}^{2}$ & 0.05 & $0.02-0.12$ & $0.01-0.10$ \\
\hline$\sigma_{m_{2} m_{3}}$ & 0.002 & $-0.02-0.02$ & $-0.01-0.02$ \\
\hline$\sigma_{m_{3}}^{2}$ & 0.02 & $0.01-0.04$ & $0.01-0.03$ \\
\hline
\end{tabular}

* For all estimates, a and m, represent the direct and maternal genetic effect respectively, and the indices 1, 2 and 3 represent hygienic behavior at 24, 48 and 72 hours, respectively. Variances are characterized by $\mathrm{m}$ or a, with the same index; the remaining features characterize the covariances.

Direct heritability estimates for hygienic behavior at 24 (0.28), 48 (0.15) and 72 hours (0.24) were lower than those found by Harbo \& Harris (1999), which was 0.65 at 24 hours. Those authors suggested that a heritability value higher than 0.25 is indicative of potential selection. Boecking et al. (2000) found heritability estimate of 0.36 through removal of perforated brood from 13 to 15 hours.

In descending order, genetic correlation with hygienic behavior between 24 and 48 hours presented the highest value (0.49), followed by the correlation observed between 48 and 72 hours (0.47) and between 24 and 72 hours (0.40). Phenotypic correlations were lower than genetic: 0.26 (24 and 48 hours), 0.31 (24 and 72 hours) and 0.20 (48 and 72 hours). Boecking et al. (2000) found genetic correlation of 0.61 and phenotypic correlation of 0.11 between Varroa destructor infestation and removal of dead capped brood.
Maternal genetic heritability estimates obtained in this study for hygienic behavior at 24 (0.23), 48 (0.29) and 72 hours $(0.27)$ notably indicate the possibility of selecting this effect for hygienic behavior of Africanized honeybees, especially at 48 hours. The influence of the queen on hygienic behavior was noticeable at the three periods. This effect reflects the ability of the queen to produce greater or smaller number of workers and possibly pheromones that influence those workers.

Genetic correlations between direct and maternal additive effects were: - 0.12 (24 hours), 0.09 (48 hours) and 0.08 (72 hours), indicating that, for hygienic behavior at 24 and 72 hours, the selection aiming to improve the additive direct effects does not affect the maternal genetic effects.

When hygienic behavior was determined at 48 hours, the higher maternal heritability resulted in lower direct 
heritability, indicating environmental contribution of the queen for hygienic behavior of the colony at 48 hours.

The highest estimate of heritability for hygienic behavior was at 24 hours (0.28), which presented genetic correlations of 0.49 and 0.40 for hygienic behavior at 48 and 72 hours respectively. Indicating the existence of higher genetic differences between colonies for dead capped brood removal at 24 hours. However, colonies with low genetic value for hygienic behavior at 24 hours may present high genetic value to the estimates obtained at 48 and 72 hours.

Thus, selection for hygienic behavior at 24 hours would lead to higher genetic gain for this trait. However, the selection over generations could reduce the genetic variability for hygienic behavior at 24 hours and the selection by hygienic behavior at 72 hours could become more efficient.

Quantifying direct and maternal effects within the proposed model confirmed the effect of the queen genes on hygienic behavior displayed by workers and allowed a highly accurate estimation of variance components within the available population studied. The use of a more adequate model in a breeding program for hygienic behavior provides a better description and results in highly accurate estimates of genetic values.

Table 3 - Estimates of permanent environmental covariance components $\left(\sigma_{i}^{2}\right)$ and credible intervals and high density areas at $90 \%$ in three trait analysis for percentage of dead capped brood removal of Africanized honeybees

\begin{tabular}{|c|c|c|c|}
\hline \multirow[t]{2}{*}{ Trait } & \multicolumn{3}{|c|}{ Estimate } \\
\hline & At 24 hours & At 48 hours & At 72 hours \\
\hline Hygienic behavior at 24 hours & $\begin{array}{c}0.03 \\
(0.01-0.05)^{*}(0.01-0.04)^{* *}\end{array}$ & & \\
\hline Hygienic behavior at 48 hours & $\begin{array}{c}0.0003 \\
(-0.02-0.03)(-0.02-0.03)\end{array}$ & $\begin{array}{c}0.08 \\
(0.02-0.23)(0.01-0.16)\end{array}$ & \\
\hline Hygienic behavior at 72 hours & $\begin{array}{c}0.004 \\
(-0.001-0.02)(-0.007-0.01)\end{array}$ & $\begin{array}{c}0.0003 \\
(-0.02-0.02)(-0.02-0.02)\end{array}$ & $\begin{array}{c}0.02 \\
(0.01-0.03)(0.01-0.03)\end{array}$ \\
\hline
\end{tabular}

* Credible interval at $90 \%$; ** High density area.

Table 4 - Residual covariance components $\left(\sigma_{\mathrm{e}}^{2}\right)$, credible intervals and high density areas at 90\% in tri-trait analysis for percentage of dead capped brood in Africanized honeybees

\begin{tabular}{|c|c|c|c|}
\hline \multirow[t]{2}{*}{ Trait } & \multicolumn{3}{|c|}{ Estimate } \\
\hline & At 24 hours & At 48 hours & At 72 hours \\
\hline Hygienic behavior at 24 hours & $\begin{array}{c}0.03 \\
(0.02-0.05)^{*}(0.02-0.05)^{* *}\end{array}$ & & \\
\hline Hygienic behavior at 48 hours & $\begin{array}{c}0,02 \\
(0.01-0.03)(0.01-0.03)\end{array}$ & $\begin{array}{c}0.02 \\
(0.01-0.04)(0.01-0.04)\end{array}$ & \\
\hline Hygienic behavior at 72 hours & $\begin{array}{c}0.01 \\
(0.01-0.02)(0.01-0.02) \\
\end{array}$ & $\begin{array}{c}0.01 \\
(0.01-0.02)(0.01-0.02) \\
\end{array}$ & $\begin{array}{l}0.02 \\
(0.01-0.03)(0.01-0.03) \\
\end{array}$ \\
\hline
\end{tabular}

* Credible interval at $90 \%$; ** High density area at $90 \%$.

Table 5 - Phenotypic covariance components $\left(\sigma_{y}^{2}\right)$, credible intervals and high density areas at $90 \%$ in three trait analysis for percentage of dead capped brood removal of Africanized honeybees

\begin{tabular}{|c|c|c|c|}
\hline \multirow[t]{2}{*}{ Trait } & \multicolumn{3}{|c|}{ Estimate } \\
\hline & At 24 hours & At 48 hours & At 72 hours \\
\hline Hygienic behavior at 24 hours & $\begin{array}{c}0.11 \\
(0.08-0.14)^{*}(0.08-0.14)^{* *}\end{array}$ & & \\
\hline Hygienic behavior at 48 hours & $\begin{array}{c}0.03 \\
(-0.01-0.08)(-0.005-0.07)\end{array}$ & $\begin{array}{c}0.19 \\
(0.10-0.36)(0.10-0.29)\end{array}$ & \\
\hline Hygienic behavior at 72 hours & $\begin{array}{c}0.03 \\
(0.01-0.05)(0.006-0.05)\end{array}$ & $\begin{array}{c}0.02 \\
(-0.01-0.05)(-0.01-0.05)\end{array}$ & $\begin{array}{c}0.08 \\
(0.06-0.10)(0.06-0.10)\end{array}$ \\
\hline
\end{tabular}

* Credible interval at $90 \% ; * *$ High density area at $90 \%$. 
Table 6 - Estimates of heritability: direct $\left(h_{a}^{2}\right)$, maternal $\left(h_{m}^{2}\right)$, genetic $\left(r_{g}\right)$ and phenotypic $\left(r_{y}\right)$ correlations, credible intervals and high density areas at $90 \%$ in three trait analysis for hygienic behavior of Africanized honeybees

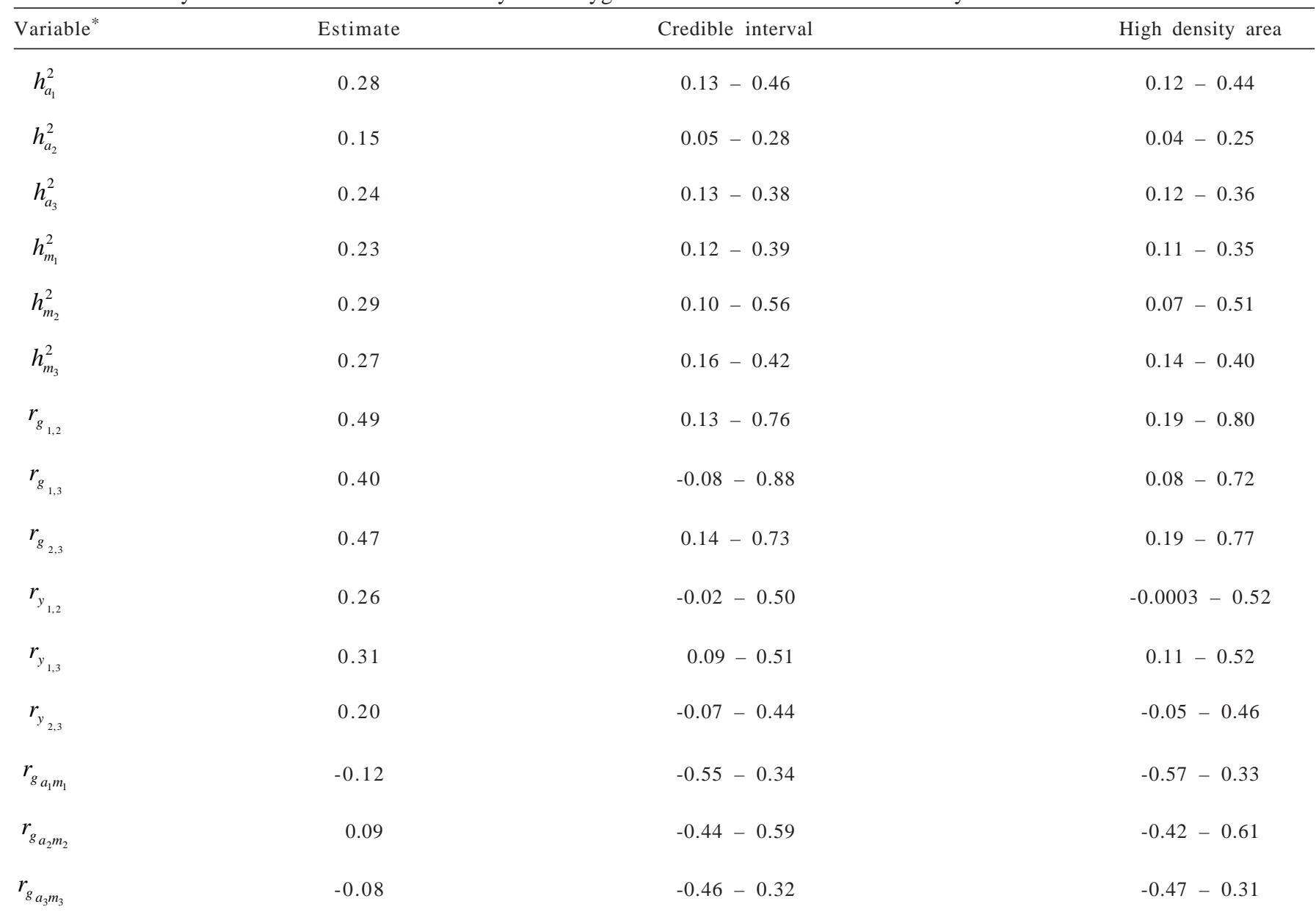

* For all estimates, $a$ and $m$ represent the direct and maternal genetic effects, respectively, and the indices 1,2 and 3 represents hygienic behavior at 24 , 48 and 72 hours respectively; heritability values are represented by $h^{2}$, genetic and phenotypic correlations by $r_{g}$ and $r_{y}$, respectively.

\section{Conclusions}

The number of dead broods removed within 24 hours is an efficient selection criterion to improve hygienic behavior, as it was evidenced with a model that includes genetic effects of queen and workers separately. However, the moderate genetic correlation with the number of dead capped broods removed until 48 and 72 hours indicates that after generations of selection, these traits can become more efficient criteria for selection.

\section{Acknowledgements}

The authors would like to thank Capes for the scholarship grants, and the technician from Setor de Apicultura of FEI-UEM, Roberto Alvarez, for helping with data collection.

\section{References}

BIENEFELD, K.; EHRHARDT, K.; REINHARDT, F. Genetic evaluation in the honey bee considering queen and worker effects - A BLUP-Animal Model approach. Apidologie, v.38, p.77-85, 2007.

BIENEFELD, K.; PIRCHNER, F. Heritabilities for several colony traits in the honeybee (Apis mellifera carnica). Apidologie, v.21, p.175-183, 1990.

BOECKING, O.; BIENEFELD, K.; DRESCHER, W. Heritability of the varroa-specific hygienic behavior in honey bees (Hymenoptera: Apidae). Journal of Animal Breeding and Genetics, v.117, p.417- 424, 2000.

DOOLITTLE, G.M. Scientific queen-rearing as practically applied. Chicago: Ills, 1889. 163p.

CASELLA, G.; GEORGE, E. Explainig the Gibbs Sampler. The American Statistical, v.46, p.167-174, 1992.

CHEVALET, C.; CORNUET, J.M. Étude théorique sur la selection du caractère production de miel" chez l'abeille. I. Modèle génétique et statistique. Apidologie, v.13, p.39-65, 1982.

GILLIAM, M.; TABER, S.; LORENZ, B.G.J. et al. Hygienic honey bees and antagonistic normal microflora for control of chalkbrood disease. In: CONGRESSO INTERNACIONAL DE 
APICUlturA, 32., 1989, Rio de Janeiro. Anais... Rio de Janeiro: Apimondia, 1989. p.227.

GONÇALVES, L.S.; KERR, W.E. Genética, Seleção e Melhoramento. 1. Noções sobre genética e melhoramento em abelhas. In: CONGRESSO BRASILEIRO DE APICULTURA, 1., 1970, Florianópolis. Anais... Florianópolis: CBA, 1970. p.8-36.

HARBO J.R.; HARRIS, J.W. Heritability in honey bees (Hymenoptera: Apidae) of characteristics associated with resistance to Varroa jacobsoni (Mesostigmata: Varroidae). Journal of Economic Entomology, v.92, n.2, p.261-265, 1999.

LAPIDGE, K.L.; OLDROYD, B.P.; SPIVAK, M. Seven suggestive quantitative loci influence hygienic behavior of honey bees. Naturwissenschaften, v.89, p.565-568, 2002.

MILNE, C.P. Estimates of heritabilities of and genetic correlation between two components of honey bee (Hymenoptera: Apidae) hygienic behavior: uncapping and removing. Annals of the Entomological Society of America, v.78, p.841-844, 1985.

MILNE, C.P. Honey bee (Hymenoptera: Apidae) hygienic behaviour and resistance to chalkbrood. Annals of the Entomological Society of America, v.76, p.384-387, 1983.

NEWTON D.C.; CANTOWELL, G.C.; BOURQUIN, E.P. Removal of freeze-killed brood as an index of nest cleaning behavior in honeybee colonies (Apis mellifera L.). American Bee Journal, v.115, p.388-406, 1975.

NOGUEIRA-COUTO, R.H.; COUTO, L.A. Apicultura: manejo e produtos. 3.ed. Jaboticabal: FUNEP, 2006. 193p.

ROTHENBÜHLER, W.C. Behavior genetics of nest cleaning in honey bees. IV. Responses of F1 and backcross generations to disease-killed brood. American Zoology, v.4, p.111-123, 1964.

R Development Core Team. R: A language and environment for statistical computing. Vienna, Austria: R Foundation for Statistical Computing, 2007. Available at: <http://www.R-project.org>. Accessed on: July 24, 2007.

SANTOS, J.J.; MESSAGE, D. Utilização de mini-recrias para a produção de geléia real. In: CONGRESSO BRASILEIRO DE APICUlturA, 5., 1980, Viçosa, MG. Anais... Viçosa, MG: Universidade Federal de Viçosa, 1980. p.307-311.

SPIVAK, M.; DOWNEY, D.L. Field assays for hygienic behavior in honey bees (Hymenoptera: Apidae). Journal of Economic Entomology, v.91, n.1, p.64-70, 1998.

SPIVAK, M.; GILLIAM, M. Facultative expression of hygienic behaviour of honey bees in relation to disease resistance. Journal of Apicultural Research, v.32, n.3, p.147-157, 1993.

TERADA, Y.; GARÓFALO, C.A.; SAKAGAMI, S.F. Age-survival curves for workers of two eusocial bees (Apis mellifera and Plebeia droryana) in a subtropical climate, with notes on worker polyethism in Plebeia droryana. Journal of Apicultural Research, v.14, n.3/4, p.161-170, 1975.

VAN TASSEL, C.P.; VAN VLECK, L.D. A manual for use of MTGSAM. A set of fortran programs to apply gibbs sampling to animal models for variance component estimation (DRAFT) Lincoln: Departament of Agriculture/Agricultural Research Service, 1995. 86p.

WILLHAM, R.L. The covariance between relatives for characters composed contributed by related individuals. Biometrics, v.19, p.18-27, 1963. 